\title{
Estimates of genetic parameters and eigenvector indices for milk production of Holstein cows
}

\author{
R. P. Savegnago, ${ }^{*}$ G. J. M. Rosa,† B. D. Valente,† L. G. G. Herrera,† R. L. R. Carneiro,§ R. C. Sesana,§ \\ L. EI Faro,\# and D. P. Munari*1 \\ *Departamento de Ciências Exatas, Faculdade de Ciências Agrárias e Veterinárias (FCAV)/Universidade Estadual Paulista (UNESP), \\ Jaboticabal, São Paulo, Brazil 14884-900 \\ †Department of Animal Sciences, University of Wisconsin, Madison 53706 \\ $\ddagger$ Facultad de Ciencias de la Salud, Universidad Tecnológica de Pereira, Pereira, Risaralda, Colombia \\ §CRV Lagoa, Sertãozinho, São Paulo, Brazil 14174-000 \\ \#Agência Paulista de Tecnologia dos Agronegócios (APTA) Centro Leste / Secretaria de Agricultura e Abastecimento (SAA), Ribeirão Preto, \\ São Paulo, Brazil 14001-970
}

\section{ABSTRACT}

The objectives of the present study were to estimate genetic parameters of monthly test-day milk yield (TDMY) of the first lactation of Brazilian Holstein cows using random regression (RR), and to compare the genetic gains for milk production and persistency, derived from $\mathrm{RR}$ models, using eigenvector indices and selection indices that did not consider eigenvectors. The data set contained monthly TDMY of 3,543 first lactations of Brazilian Holstein cows calving between 1994 and 2011. The RR model included the fixed effect of the contemporary group (herd-month-year of test days), the covariate calving age (linear and quadratic effects), and a fourth-order regression on Legendre orthogonal polynomials of days in milk (DIM) to model the population-based mean curve. Additive genetic and nongenetic animal effects were fit as RR with 4 classes of residual variance random effect. Eigenvector indices based on the additive genetic RR covariance matrix were used to evaluate the genetic gains of milk yield and persistency compared with the traditional selection index (selection index based on breeding values of milk yield until 305 DIM). The heritability estimates for monthly TDMY ranged from $0.12 \pm 0.04$ to $0.31 \pm$ 0.04 . The estimates of additive genetic and nongenetic animal effects correlation were close to 1 at adjacent monthly TDMY, with a tendency to diminish as the time between DIM classes increased. The first eigenvector was related to the increase of the genetic response of the milk yield and the second eigenvector was related to the increase of the genetic gains of the persistency but it contributed to decrease the genetic gains for total milk yield. Therefore, using this eigenvector to improve persistency will not contribute to change the shape of

Received February 18, 2013.

Accepted July 23, 2013.

${ }^{1}$ Corresponding author: danisio@fcav.unesp.br genetic curve pattern. If the breeding goal is to improve milk production and persistency, complete sequential eigenvector indices (selection indices composite with all eigenvectors) could be used with higher economic values for persistency. However, if the breeding goal is to improve only milk yield, the traditional selection index is indicated.

Key words: eigenvalue, Legendre polynomial, persistency, random regression

\section{INTRODUCTION}

One of the main objectives in dairy cattle breeding programs is to change, genetically, the shape of the milk production curve. Total milk yield and persistency (i.e., the ability of a cow to continue to produce milk at high levels after the peak of lactation) are both of economic interest. Different statistical models have been used to genetically evaluate milk production using test-day observations. Jensen (2001) reviewed the most frequently used models for evaluating genetically the milk production.

Henderson (1982) proposed the use of random regression (RR) models in animal breeding for genetic evaluations on traits measured over time. Jamrozik et al. (1997) and van der Werf et al. (1998) reported that RR models were more appropriate for estimating the genetic parameters of test-day milk yield (TDMY) than repeatability models, because $\mathrm{RR}$ models are able to fit genetic and environmental changes in milk yield over the time. Schaeffer (2004) reviewed the applications of RR models to animal breeding and Dzomba et al. (2010) reported the advantages of RR models in relation to multi-trait models.

van der Werf et al. (1998), Strabel and Misztal (1999), Kettunen et al. (2000), and Pool et al. (2000) used RR with homogeneous residual variance to estimate genetic parameters for TDMY, but Jamrozik and Schaeffer (1997) and Jamrozik et al. (1997) identified 
problems in estimating the variance components of additive genetic and nongenetic animal effects, such as overestimation of the genetic variance when the RR considered this structure of residual variance. Several researchers have suggested the use of classes of heterogeneous residual variance (Olori et al., 1999; Rekaya et al., 1999; Brotherstone et al., 2000; Druet et al., 2003; El Faro and Albuquerque, 2003; Bignardi et al., 2009, 2011, 2012).

Persistency can be measured in different ways (Gengler, 1996; Swalve and Gengler, 1999). The RR models provide a way to calculate daily, partial, and whole-lactation predicted breeding values (EBV) and to define many measurements of genetic persistency of the lactation curve (Jamrozik et al., 1997; Swalve and Gengler, 1999). The economic importance of persistency is linked to a reduction of feed costs (Gengler, 1996). Dekkers et al. (1997) reported that cows with greater persistency were more profitable.

Gengler (1996) presented the most common definitions of persistency. Approaches exist to make the phenotypic measure of persistency independent of milk yield (Gengler, 1995; VanRaden, 1998; Grossman et al., 1999; Cole and VanRaden, 2006; Cole and Null, 2009). Other approaches define persistency as the difference between the peak yield and that at a testday in the late lactation or as the ratio of these yields (Ptak and Schaeffer, 1993; Swalve, 2000). Druet et al. (2005) reported that the first and second eigenvectors of the estimated genetic (co)variance matrix in an RR model could be interpreted as latent variables for milk yield and persistency, respectively. Another approach is to develop genetic measurements of persistency from breeding values obtained with RR models (Gengler, 1996).

Togashi and Lin (2006) developed selection indices for milk production and persistency simultaneously, derived from the eigenvectors of the additive genetic coefficients of RR models. Each eigenfunction expresses the curve patterns of the mean curve of the population for a longitudinal trait in each dimension of the additive genetic RR coefficients matrix (Kirkpatrick and Lofsvold, 1992).

Selection indices to improve genetically quantitative traits have been used to summarize a group of traits in a single value, representing the breeding objective. In doing so, a selection index allows selection of these traits jointly in a weighted manner. Then, it would be interesting to study the genetic gains of total milk production and persistency using selection indices that take into account the curve pattern of the genetic lactation curve of each eigenfunction.

The objectives of the present study were to estimate genetic parameters of monthly TDMY of the first lactation of Brazilian Holstein cows using RR, and to compare the genetic gains for milk production and persistency, derived from RR models, using eigenvector indices and selection indices that did not consider eigenvectors.

\section{MATERIALS AND METHODS}

\section{Description of the Population and Data Preparation}

A data set of 3,543 first lactations of Brazilian Holstein cows from 30 herds and calving between 1994 and 2011 were used to estimate genetic parameters of monthly TDMY. They were maintained in semi-feedlot and feedlot systems, depending on the milk yield level. The cows were fed on pasture during the rainy season (October to March) and using silage during the dry season (April to September). All animals received concentrate supplementary feed according to the milk production level. The cows in confined herds received maize (corn) silage throughout the year, in addition to the other feedstuffs described above. Milking was done mechanically 3 times a day.

The monthly TDMY were measured between 5 and 305 DIM, divided into 10 classes. The first class included milk yield between 5 and 30 DIM, the second included milk yield between 31 and 60 DIM, and so on until the last class, which included milk yield between 270 and 305 DIM. The cows with no drying-off date or those that were excluded from the dairy milk evaluation were excluded from the data. Additionally, cows with at least 3 TDMY distributed throughout the lactation, even if the cows did not have all TDMY (complete lactation), were kept in the data set.

Monthly TDMY 3 standard deviations above or below the mean of the contemporary group (CG), defined as herd-month-year of TDMY, were also excluded from the data file. Contemporary groups that had at least 3 TDMY were kept. Table 1 shows the numbers of monthly TDMY records, CG, mean, minimum, and maximum calving age, after data editing and in the pedigree structure.

\section{Estimates of Variance Components and Model Selection}

Analyses were performed using a single-trait RR model. The model included the fixed effects of CG (herd-month-year of TDMY), the covariate calving age (linear and quadratic effect), and the additive genetic and nongenetic animal random effects. A fourth-order regression on Legendre orthogonal polynomials of DIM was used to model the population-based mean curve. The fixed effects and the covariates were significant $(P$ 
Table 1. Description of the data and pedigree structure of monthly test-day milk yield (TDMY)

\begin{tabular}{lc}
\hline Item & Value \\
\hline Data structure & \\
Number of monthly TDMY & 29,477 \\
Number of contemporary groups & 1,409 \\
Mean of calving age (mo) & 27.73 \\
Minimum calving age (mo) & 18 \\
Maximum calving age (mo) & 37 \\
Pedigree structure & \\
Cows with records & 3,543 \\
Cows without records & 745 \\
Number of sires & 443 \\
Number of dams & 1,069 \\
Total number of animals in the pedigree file & 5,738 \\
\hline
\end{tabular}

$<0.01$ ) on the monthly TDMY using the least squares method by the GLM procedure of the SAS software (version 9.2; SAS Institute, 2008). The additive genetic and nongenetic animal random effects were estimated using RR on Legendre polynomials of DIM.

The general RR model can be expressed as

$$
\mathbf{y}=\mathbf{X} \boldsymbol{\beta}+\mathbf{Z a}+\mathbf{W c}+\varepsilon,
$$

where $\mathbf{y}$ is the vector of $n$ monthly TDMY; $\boldsymbol{\beta}$ is the fixed-effect vector that includes the solutions for CG (herd-month-year of TDMY) and for the covariate calving age; $\mathbf{a}$ and $\mathbf{c}$ are vectors of solutions for the additive genetic and nongenetic animal RR coefficients, respectively; $\boldsymbol{\varepsilon}$ is the vector of residuals; and $\mathbf{X}, \mathbf{Z}$, and $\mathbf{W}$ are incidence matrixes for the fixed effects, additive genetic effects, and nongenetic animal random effects, respectively.

The assumptions of the model (expectation, E, and variance, V) are as follows:

$$
\mathrm{E}\left[\begin{array}{c}
\mathbf{y} \\
\mathbf{a} \\
\mathbf{c} \\
\varepsilon
\end{array}\right]=\left[\begin{array}{c}
\mathbf{X} \boldsymbol{\beta} \\
0 \\
0 \\
0
\end{array}\right],
$$

$$
\mathrm{V}\left[\begin{array}{l}
\mathbf{a} \\
\mathbf{c} \\
\boldsymbol{\varepsilon}
\end{array}\right]=\left[\begin{array}{ccc}
\mathbf{K}_{a} \otimes \mathbf{A} & 0 & 0 \\
0 & \mathbf{K}_{c} \otimes \mathbf{I}_{\mathrm{N}_{\mathrm{A}}} & 0 \\
0 & 0 & \mathbf{R}
\end{array}\right],
$$

where $\mathbf{K}_{a}$ and $\mathbf{K}_{c}$ are the (co)variance matrixes between the RR coefficients for the additive genetic and the nongenetic animal effects, respectively; $\mathbf{A}$ is the relationship matrix; $\mathbf{I}$ is an identity matrix; $\mathrm{N}_{\mathrm{A}}$ is the number of animals with records; $\otimes$ is the Kronecker product; and $\mathbf{R}$ is the diagonal matrix containing the residual variances. In this model, we assumed no corre- lation between the $\mathrm{RR}$ coefficients for additive genetic with nongenetic animal effects.

The DIM were standardized between -1 and 1 using $w_{t}=-1+2\left[\left(t-t_{\min }\right) /\left(t_{\max }-t_{\min }\right)\right]$ (Kirkpatrick et al., 1990, 1994), in which $w_{t}$ is the standardized DIM at time $t ; t=t_{\min }, \ldots, t_{\max }$. The residual variance was considered heterogeneous, and 4 classes were used: 5 to 30 DIM, 31 to 60 DIM, 61 to 210 DIM, and 211 to 305 DIM. The REML method was used to estimate the covariance components for the monthly milk production using the WOMBAT software (Meyer, 2007), by the average information-REML algorithm, which enabled error calculations for the estimates of variance and heritability components (Fischer et al., 2004). Convergence was met when the change in value of the logarithm of the likelihood function in 2 consecutive iterations was lower than $10^{-6}$.

Fourteen different RR models were compared with identify the best order for Legendre polynomials for additive genetic and nongenetic animal effects. The order of Legendre polynomials ranged from second to fourth order for the additive genetic effect $\left(k_{a}=3\right.$ to 5 coefficients, where $k$ is the number of coefficients of Legendre polynomials) and from second to sixth-order for the nongenetic animal effects $\left(k_{c}=3\right.$ to 7 coefficients). The Bayesian information criterion (Schwarz, 1978) was used for model selection. Model 3 (Table 2) presented the lowest Bayesian information criterion value, with $k_{a}=3$ (second-order Legendre polynomial), $k_{c}=6$ (fifth-order Legendre polynomial), and 4 classes of residual variance (from 5 to 30 DIM; from 31 to 60 DIM; from 61 to 210 DIM; and from 211 to 305 DIM). Therefore, this model was chosen to estimate the genetic parameters of TDMY.

\section{Estimates of Additive Genetic and Nongenetic Animal (Co) Variances of TDMY}

In matrix notation, the orthogonal Legendre polynomials can be written as $\mathbf{\Phi}=\mathbf{M} \boldsymbol{\Gamma}$, in which $\mathbf{M}$ is the matrix with the polynomial values for $w_{t}$ of order ( $t$ by $k$ ), in which $t$ is the DIM, $k$ is the number of parameters of the polynomial, and $\boldsymbol{\Gamma}$ is the matrix with the coefficients of the standardized Legendre polynomials (Mrode, 2005). The additive genetic and the nongenetic animal (co)variance matrices for monthly TDMY ( $\hat{\mathbf{G}}$ and $\hat{\mathbf{C}}$, respectively) were calculated by pre- and postmultiplying the $\mathbf{K}_{a}$ and $\mathbf{K}_{c}$ matrices by $\boldsymbol{\Phi}$, resulting in $\hat{\mathbf{G}}=\boldsymbol{\Phi} \mathbf{K}_{a} \boldsymbol{\Phi}^{\prime}$ and $\hat{\mathbf{C}}=\boldsymbol{\Phi} \mathbf{K}_{c} \boldsymbol{\Phi}^{\prime}$, in which $\boldsymbol{\Phi}^{\prime}$ is the transpose of $\boldsymbol{\Phi}$.

The standard errors of the additive genetic correlation (Equation [3]) and nongenetic animal effect correlation (Equation [4]) were calculated in accordance 
Table 2. Number of parameters in the random regression model (nP), logarithm of the maximum likelihood function ( $\log \mathrm{L})$, and Bayesian information criterion (BIC) for each model

\begin{tabular}{llccc}
\hline Model & $\mathrm{k}_{\mathrm{a}}, \mathrm{k}_{\mathrm{c}}, \varepsilon^{1}$ & $\mathrm{nP}$ & $\log \mathrm{L}$ & $\mathrm{BIC}$ \\
\hline 1 & $3,4,4$ & 20 & $-52,480.74$ & $105,166.32$ \\
2 & $3,5,4$ & 25 & $-52,423.35$ & $105,102.75$ \\
3 & $3,6,4$ & 31 & $-52,355.17$ & $105,027.84$ \\
4 & $3,7,4$ & 38 & $-52,343.77$ & $105,076.75$ \\
5 & $4,3,4$ & 20 & $-52,483.57$ & $105,171.98$ \\
6 & $4,4,4$ & 24 & $-52,463.67$ & $105,173.15$ \\
7 & $4,5,4$ & 29 & $-52,405.82$ & $105,108.66$ \\
8 & $4,6,4$ & 35 & $-52,335.79$ & $105,030.05$ \\
9 & $4,7,4$ & 42 & $-52,324.04$ & $105,078.25$ \\
10 & $5,3,4$ & 25 & $-52,439.08$ & $105,134.21$ \\
11 & $5,4,4$ & 29 & $-52,415.92$ & $105,128.86$ \\
12 & $5,5,4$ & 34 & $-52,396.09$ & $105,140.41$ \\
13 & $5,6,4$ & 40 & $-52,326.06$ & $105,061.80$ \\
14 & $5,7,4$ & 47 & $-52,314.39$ & $105,110.17$ \\
\hline
\end{tabular}

${ }^{1} \mathrm{k}_{\mathrm{a}}$ and $\mathrm{k}_{\mathrm{c}}=$ numbers of parameters in the Legendre polynomials for fitting the additive genetic random effects and the nongenetic animal effects, respectively; $\varepsilon=$ number of classes of residual effects.

with the formula suggested by Reeve (1955) and Robertson (1959), given by

$$
\begin{gathered}
\sigma_{\left(\mathrm{r}_{\mathrm{a}}\right)}=\frac{1-\mathrm{r}_{a}^{2}}{\sqrt{2}} \sqrt{\frac{\sigma_{\left(\mathrm{h}_{\mathrm{X}}^{2}\right)^{\sigma}\left(\mathrm{h}_{\mathrm{Y}}^{2}\right)}}{\mathrm{h}_{\mathrm{X}}^{2} \mathrm{~h}_{\mathrm{Y}}^{2}}}, \\
\sigma_{\left(\mathrm{r}_{\mathrm{c}}\right)}=\frac{1-r_{c}^{2}}{\sqrt{2}} \sqrt{\frac{\sigma_{\left(\mathrm{c}_{\mathrm{X}}^{2}\right)^{\sigma}\left(\mathrm{c}_{\mathrm{Y}}^{2}\right)}}{\mathrm{c}_{\mathrm{X}}^{2} \mathrm{c}_{\mathrm{Y}}^{2}}},
\end{gathered}
$$

where $\sigma_{\left(\mathrm{r}_{\mathrm{a}}\right)}$ and $\sigma_{\left(\mathrm{r}_{c}\right)}$ are the standard errors of the additive genetic correlation $\left(\mathrm{r}_{\mathrm{a}}\right)$ and nongenetic animal effect correlation $\left(\mathrm{r}_{\mathrm{c}}\right)$ between the class of DIM X and Y; $\sigma_{\left(\mathrm{h}_{\mathrm{X}}^{2}\right)}$ and $\sigma_{\left(\mathrm{h}_{\mathrm{Y}}^{2}\right)}$ are the standard errors of heritability estimates of DIM X and Y classes, respectively; $\sigma_{\left(c_{\mathrm{x}}^{2}\right)}$ and $\sigma_{\left(\mathrm{c}_{Y}^{2}\right)}$ are the standard errors of the proportion of nongenetic animal effect of DIM X $\left(\mathrm{c}_{\mathrm{X}}^{2}\right)$ and $\mathrm{Y}\left(\mathrm{c}_{\mathrm{Y}}^{2}\right)$ classes, respectively.

\section{Selection Indices for Milk Production and Persistency}

We compared the genetic gains of milk yield and persistency using 3 different selection indices: selection index based on individual eigenvectors, based on sequential eigenvectors, and selection index that did not use the eigenvectors of the additive genetic RR coefficients; that is, a traditional selection index based on the breeding values of milk production until 305 DIM $\left(\mathrm{I}_{M Y 305}\right.$; Lin and Togashi, 2005; Togashi and Lin, 2006). The total milk yield from 5 to 305 DIM and the persistency were calculated from the RR model.

Random regression models can provide breeding values for any measurement of lactation yield (e.g., day yields, monthly yields, partial yields, total yields, or other lactation yields). In this study, persistency was defined as the difference between the breeding values of 280 and 60 DIM $\left(\mathrm{EBV}_{280}-\mathrm{EBV}_{60}\right.$; Jamrozik et al., 1997), because Togashi and Lin (2004) compared the efficiency of 5 selection criteria for milk yield and persistency, in terms of genetic changes, and they found the greatest genetic gain using this definition of persistency.

This measurement of persistency was used in all indices described below to calculate the genetic gain for this trait. It is important to stress that phenotypic values of persistency were not directly available in this study. All the results were based on genetic measurements from the RR model. The eigenvectors of the additive genetic $\mathrm{RR}$ coefficient matrix were used to construct selection indices to assess their effect on lactation milk and persistency. The eigenvectors are orthogonal and this property can be used to analyze each eigenfunction independently (individual) or combined (sequential). The individual eigenvector indices indicated the genetic gains in each dimension of the additive genetic RR coefficient matrix, given the respective proportion of the variation in each eigenvalue. The sequential eigenvector indices were used to explore how the genetic gains would be when the information of each eigenvector of $\mathbf{K}_{a}$ was considered sequentially.

\section{Individual Eigenvector Indices}

The individual eigenvector indices were calculated as

$$
\mathrm{I}_{j}=\mathbf{e}_{j}^{\prime} \mathbf{\alpha}_{i}
$$

where $I_{j}$ is the $j$ th individual selection index based on the $j$ th eigenvector; $\mathbf{e}_{j}^{\prime}$ is a line vector of the $j$ th eigen- 
vector of order 1 by $\mathrm{k}$; and $\boldsymbol{\alpha}_{i}$ is the column vector of order $\mathrm{k}$ by 1 for the solution of the additive genetic RR coefficients of the $i$ th animal, fitted by Legendre polynomial of degree $(k-1)$.

The correlated response from each $\operatorname{DIM}(\boldsymbol{\Delta})$; that is, 5 to 305 DIM, to selection on $\mathrm{I}_{j}$ is

$$
\boldsymbol{\Delta}=\mathbf{\Phi} \mathbf{K}_{a} \mathbf{e}_{j}\left(\frac{i}{\sigma_{I_{j}}}\right),
$$

where $\boldsymbol{\Delta}=\left[\begin{array}{llll}\Delta G_{5} & \Delta G_{6} & \cdots & \Delta G_{305}\end{array}\right]^{\prime}$ is a transpose vector for the genetic gain in milk production on each DIM; $i$ is the selection intensity; $\sigma_{\mathrm{I}_{j}}^{2}=\mathbf{e}_{j}{ }^{\prime} \mathbf{K e}_{j}=\lambda_{j}$ is the variance of the $j$ th index; and $\lambda_{j}$ is the $j$ th eigenvalue of $\mathbf{K}_{a}$.

\section{Sequential Eigenvector Indices Using Economic Weights for Milk Yield and Persistency}

The sequential eigenvectors indices $\mathrm{IS}_{1}, \mathrm{IS}_{2}, \ldots, \mathrm{IS}_{n}$ were calculated as follows:

$$
\mathrm{IS}_{n}=\mathbf{b}^{\prime} \mathbf{E}^{\prime} \boldsymbol{\alpha}_{i}
$$

where $\mathbf{b}$ is a vector 1 by $\mathrm{k}$ for the coefficients of the selection index and $\mathbf{E}^{\prime}$ is the transposed matrix of the eigenvectors of the matrix $\mathbf{K}_{a}$.

Considering net merit as a combination of milk yield and persistency (more details in Togashi and Lin, 2006), the selection index coefficients were calculated as follows:

$$
\mathbf{b}=\mathbf{D}^{-\mathbf{1}} \mathbf{E}^{\prime} \mathbf{K}_{\mathrm{a}}\left[q_{1} \boldsymbol{\Phi}^{\prime *} \mathbf{1}+q_{2}\left(\boldsymbol{\Phi}_{280}^{\prime}-\boldsymbol{\Phi}_{60}^{\prime}\right)\right],
$$

where $\mathbf{D}^{-1}$ is the inverse of the diagonal eigenvalues of the matrix $\mathbf{K}_{a} ; \mathbf{1}$ is the vector of ones of appropriate dimensions; $\boldsymbol{\Phi}^{\prime *}$ is a ( $k$ by 299) matrix obtained by deleting the rows of $\boldsymbol{\Phi}$ corresponding to 60 and 280 DIM; and $q_{1}$ and $q_{2}$ are economic weights for milk yield and persistency, respectively. The exclusion of $\boldsymbol{\Phi}_{60}^{\prime}$ and $\boldsymbol{\Phi}_{280}^{\prime}$ from $\Phi^{\prime *}$ was done to avoid the duplication of the information of persistency on milk yield in the net merit.

The correlated response from 5 to $305 \operatorname{DIM}(\boldsymbol{\Delta})$ to selection on $\mathrm{IS}_{n}$ was

$$
\boldsymbol{\Delta}=\mathbf{\Phi} \mathbf{K}_{a} \mathbf{E b}\left(\frac{i}{\sigma_{I S_{(n)}}}\right),
$$

where $\sigma_{I S_{(n)}}^{2}=\mathbf{b}^{\prime} \mathbf{D b}$.

The complete index was given by $I S_{n}$, which contains all the eigenvectors; $I S_{(n-1)}$ was given by removing the last eigenvector the $I S_{1}$ index, which consists of the first eigenvector alone.

It is difficult to find in the literature the relative economic weights between milk yield and persistency (Togashi and Lin, 2006); therefore, economic weights were assumed to be $q_{1}: q_{2}=1: 1, q_{1}: q_{2}=1: 25, q_{1}: q_{2}=$ 1:50, $q_{1}: q_{2}=1: 75$, and $q_{1}: q_{2}=1: 100$. Assigned relative economic weights can obviously be considered arbitrary, but the objective of this study was not to find the best values but to assess the response when these values were used.

\section{Selection Indices Based on Lactation EBV (Traditional Selection Indices)}

The traditional index did not use the eigenvector decomposition of $\mathbf{K}_{a}$. The traditional selection index $\left(\mathrm{I}_{M Y 305}\right)$ based on EBV milk yields was given by $\mathrm{I}_{M Y 305}=\mathbf{1}^{\prime} \mathbf{\Phi} \boldsymbol{\alpha}$, and the genetic gains in each DIM were calculated by $\boldsymbol{\Delta}=\mathrm{i} \sqrt{\mathbf{1}^{\prime} \mathbf{G} \mathbf{1}}$.

The correlated response from 5 to 305 DIM to selection on individual or sequential eigenvector indices were compared with the correlated response from 5 to 305 DIM to selection on traditional index for milk production and persistency. The correlated responses of the persistency $\left(\Delta G_{P}\right)$ by selecting indices values (individual, sequential, and traditional indices) were calculated as differences between genetic gains for 280 DIM minus 60 DIM $\left(\Delta G_{280}-\Delta G_{60}\right)$. The correlated responses of the total milk yield from 5 to 305 DIM $\left(\Delta G_{L}\right)$ by selecting indices values were calculated by the summation of genetic gains from each DIM. The selection intensity was set as 1 in all selection indices in this study.

\section{RESULTS AND DISCUSSION}

The overall mean $( \pm \mathrm{SD})$ for TDMY at the first lactation was $26 \pm 8.26 \mathrm{~kg}$. The means of monthly TDMY (Table 3) indicated that the greatest production occurred between 61 and 150 DIM.

The variance components are shown in Figure 1. The heritability estimates for monthly TDMY in this study (Table 4) were similar to those reported by Strabel and Misztal (1999), Brotherstone et al. (2000), Kettunen et al. (2000), Araújo et al. (2006), and Bignardi et al. $(2009,2011)$ for Holstein cows. The estimates for the nongenetic animal effect proportion (Table 4) indicated that a large proportion of the phenotypic variation in the monthly TDMY was due to the fact that individual cows often had the same milk yield over multiple test days. So, only a few milk yield measurements on each monthly TDMY may be adequate for representing the animals' real production capacity. 
Table 3. Days in milk, number of records, mean, standard deviations (SD), coefficient of variation (CV), and minimum and maximum values for monthly test-day milk yield (TDMY)

\begin{tabular}{llcccccc}
\hline $\begin{array}{l}\text { Class of } \\
\text { TDMY }\end{array}$ & DIM & $\begin{array}{c}\text { Records } \\
\text { (no.) }\end{array}$ & $\begin{array}{c}\text { Mean } \\
(\mathrm{kg})\end{array}$ & $\begin{array}{c}\text { SD } \\
(\mathrm{kg})\end{array}$ & $\begin{array}{c}\text { CV } \\
(\%)\end{array}$ & $\begin{array}{c}\text { Minimum } \\
(\mathrm{kg})\end{array}$ & $\begin{array}{c}\text { Maximum } \\
(\mathrm{kg})\end{array}$ \\
\hline 1 & 5 to 30 & 2,499 & 23.39 & 6.74 & 28.82 & 4.0 & 50.0 \\
2 & 31 to 60 & 3,058 & 27.50 & 7.61 & 27.68 & 3.0 & 56.0 \\
3 & 61 to 90 & 3,151 & 28.31 & 7.94 & 28.04 & 4.0 & 56.0 \\
4 & 91 to 120 & 3,124 & 28.28 & 8.11 & 28.67 & 4.0 & 52.0 \\
5 & 121 to 150 & 3,091 & 27.80 & 8.22 & 29.58 & 4.0 & 56.0 \\
6 & 151 to 180 & 3,144 & 27.05 & 8.19 & 30.26 & 5.0 & 52.0 \\
7 & 181 to 210 & 3,102 & 26.28 & 8.19 & 31.18 & 3.0 & 52.0 \\
8 & 211 to 240 & 2,953 & 25.10 & 8.14 & 32.42 & 2.0 & 50.0 \\
9 & 241 to 270 & 2,794 & 23.94 & 8.11 & 33.87 & 3.0 & 49.0 \\
10 & 271 to 305 & 2,561 & 22.49 & 8.07 & 35.89 & 3.0 & 48.0 \\
\hline
\end{tabular}

The estimates of additive genetic correlation and nongenetic animal effect correlation for monthly TDMY (Table 5) were high in adjacent TDMY, with a trend to decrease as time increased between the months. This same trend was reported by Kettunen et al. (2000), Cobuci et al. (2005), and Bignardi et al. (2009, 2011). The high nongenetic animal effect correlation indicated that the animals' production capacity due to the nongenetic animal effect in a specific month might indicate similar milk production in other periods within the lactation.

The covariance matrix for the additive genetic coefficients of the second-order Legendre polynomials $\left(\mathbf{K}_{a}\right)$ was as follows:

$$
\mathbf{K}_{a}=\left[\begin{array}{ccc}
9.9986 & 2.0217 & -1.2288 \\
2.0217 & 1.3176 & 0.0043 \\
-1.2288 & 0.0432 & 1.2103
\end{array}\right]
$$

The eigenvalues $\left(\lambda_{j}\right)$ of $\mathbf{K}_{a}$ were $10.60,1.25$, and 0.68 , and they explained 85,10 , and $5 \%$ of the genetic variation of the RR coefficients, respectively. The eigenvectors from each eigenvalue are presented in Table 6 .

The eigenvalues of $\mathbf{K}_{a}$ were similar to those reported by van der Werf et al. (1998), Olori et al. (1999), Pool et al. (2000), Druet et al. (2003), and Togashi and Lin (2006). Models with Legendre polynomials that were higher than third order $\left(k_{a} \geq 4\right)$ for the additive genetic effect did not have a better fit and did not add genetic information to the model, because the first 2 or 3 eigenvalues of $\mathbf{K}_{a}$ generally explained almost all of the additive genetic variation of the $\mathrm{RR}$ coefficients, thereby explaining the variation in level and shape of the genetic curve.

The patterns of genetic gains from 5 to 305 DIM obtained by individual eigenvector indices based on the eigenvectors are in Figure 2. The genetic gains for milk yield $\left(\Delta G_{L}\right)$ and persistency of milk production $\left(\Delta G_{P}\right)$ obtained by individual eigenvector indices, sequential eigenvector indices, and the traditional selection index are given in Table 7 . The daily genetic gains of the first individual eigenvector index increased from 0.74 $\mathrm{kg}$ at 5 DIM to $2.74 \mathrm{~kg}$ between 211 and 228 DIM and then remained stable until the end of the first lactation (Figure 2). The genetic gains of the second individual eigenvector index were positive from 5 to 34 DIM and from 220 to 305 DIM and were negative from 36 to 218 DIM (Figure 2). The genetic gains of the third individual eigenvector index were positive until 120 DIM and close to zero in subsequent DIM.

The first element of the leading eigenvector in the first lactation (0.9692) was the largest, indicating that the leading eigenvector contributed mainly toward variation

Table 4. Heritability estimates $\left(h^{2}\right)$ and proportion of variance due to nongenetic animal effect $\left(c^{2}\right)$ for monthly test-day milk yield (TDMY)

\begin{tabular}{llcc}
\hline $\begin{array}{l}\text { Class of } \\
\text { TDMY }\end{array}$ & DIM & $h^{2}( \pm \mathrm{SE})$ & $c^{2}( \pm \mathrm{SE})$ \\
\hline 1 & 5 to 30 & $0.12 \pm 0.04$ & $0.57 \pm 0.07$ \\
2 & 31 to 60 & $0.12 \pm 0.03$ & $0.62 \pm 0.03$ \\
3 & 61 to 90 & $0.16 \pm 0.03$ & $0.60 \pm 0.03$ \\
4 & 91 to 120 & $0.22 \pm 0.04$ & $0.53 \pm 0.03$ \\
5 & 121 to 150 & $0.29 \pm 0.04$ & $0.48 \pm 0.04$ \\
6 & 151 to 180 & $0.31 \pm 0.04$ & $0.45 \pm 0.04$ \\
7 & 181 to 210 & $0.31 \pm 0.04$ & $0.45 \pm 0.04$ \\
8 & 211 to 240 & $0.28 \pm 0.04$ & $0.46 \pm 0.04$ \\
9 & 241 to 270 & $0.26 \pm 0.04$ & $0.53 \pm 0.04$ \\
10 & 271 to 305 & $0.29 \pm 0.04$ & $0.52 \pm 0.04$ \\
\hline
\end{tabular}


Table 5. Additive genetic correlations (above the diagonal) and nongenetic animal effect correlations (below the diagonal) between the monthly test-day milk yields ${ }^{1}$

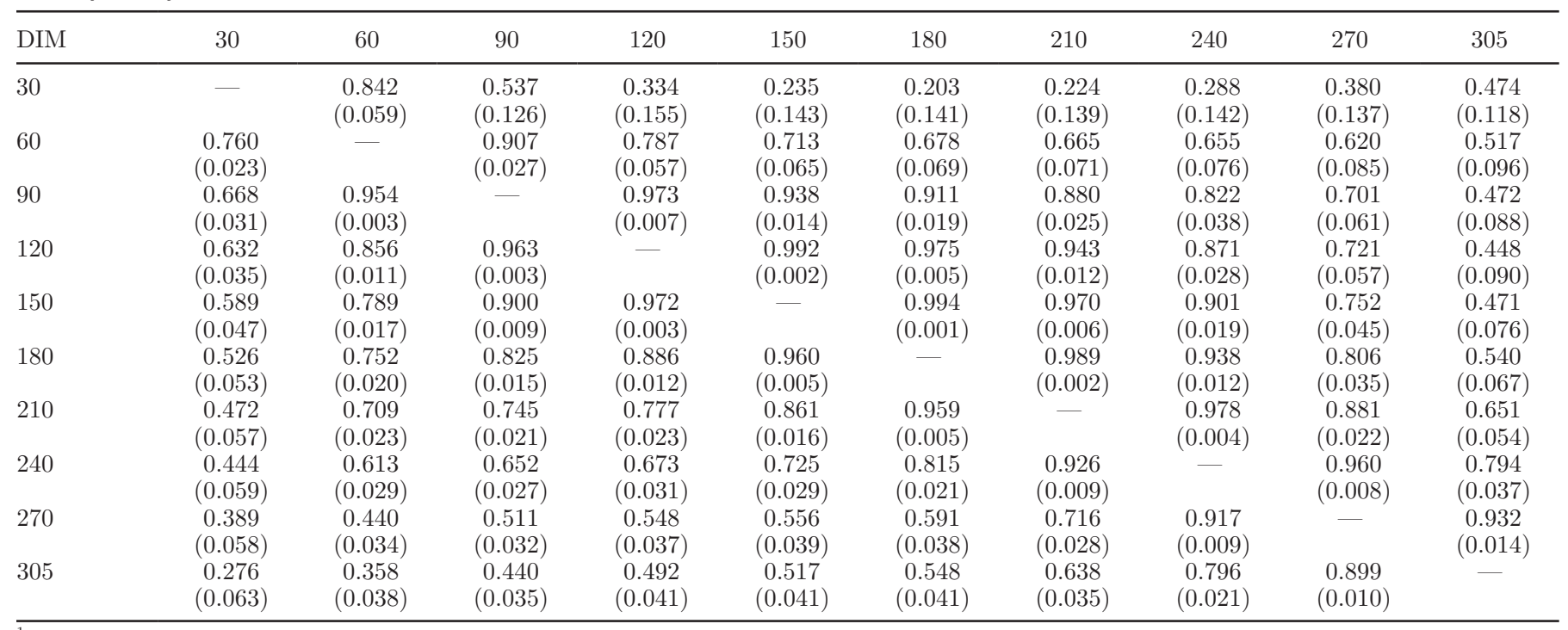

${ }^{1}$ Standard errors are in parentheses.

in the constant term of the Legendre polynomial over the course of the lactation period. Selecting animals based on this eigenvector index would change mainly the cow's milk yield and consequently the persistency (Figure 2). For the second eigenvector, the quadratic term of the Legendre polynomial had the largest value in this eigenvector, showing a quadratic curve pattern for this eigenvector index. Thus, selection based on the second individual eigenvector index could result in genetic gains in the beginning and the end of the lactation, resulting in high genetic gains for persistency, but would also result in negative genetic gains for total milk yield. The third individual eigenvector index was the least important, because the genetic gain for milk yield was very low compared with that obtained with the first individual eigenvector index, and the genetic gain for persistency was negative.

The genetic gain for milk yield and persistency was almost the same using sequential eigenvector indices with 1,2 , or 3 eigenvectors $\left(\mathrm{IS}_{1}, \mathrm{IS}_{2}\right.$, or $\mathrm{IS}_{3}$, respectively) when the following economic weights were used $q_{1}: q_{2}=$ $1: 1$ and $q_{1}: q_{2}=1: 25$ (Table 7 ). The genetic gain for milk yield was almost the same when using traditional index and sequential eigenvector indices with $q_{1}: q_{2}=1: 1$ and $q_{1}: q_{2}=1: 25$, and the genetic gains for persistency were similar for the traditional selection index and complete sequential eigenvector indices $\left(\mathrm{IS}_{3}\right)$ with $q_{1}: q_{2}=1: 25$ and $q_{1}: q_{2}=1: 50$.

The genetic gains for milk yield and persistency were the same in all situations for $\mathrm{IS}_{1}$. However, when the

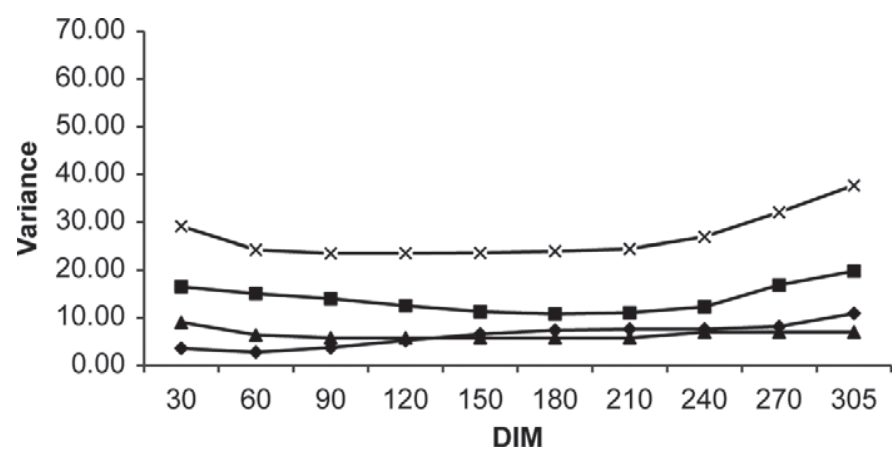

Figure 1. Variance components for direct additive genetic $\left(\sigma_{a}^{2} ; \bullet\right)$, nonadditive genetic $\left(\sigma_{c}^{2} ; \mathbf{\square}\right)$, residual $\left(\sigma_{e}^{2} ; \boldsymbol{\Delta}\right)$, and phenotype effects $\left(\sigma_{p}^{2} ; \times\right)$ for monthly test-day milk yield.

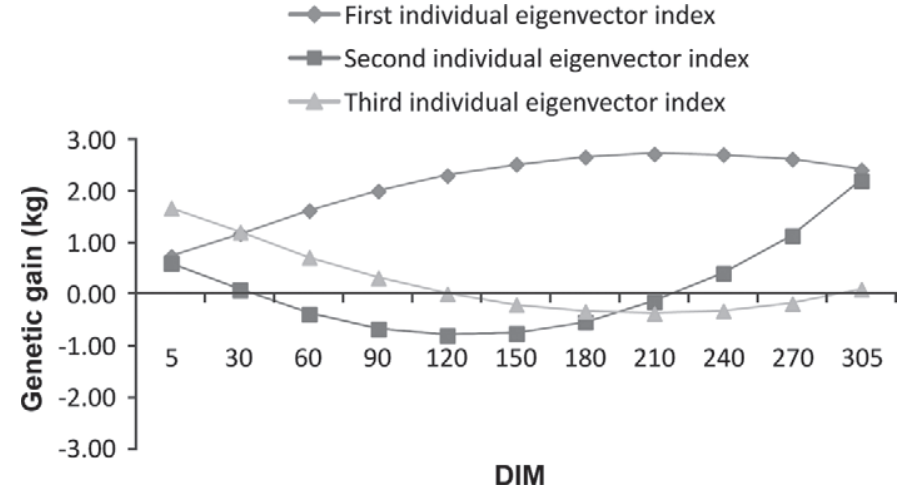

Figure 2. Genetic response pattern over the first lactation relating to individual eigenvector indices. 
Table 6. Eigenvectors of the additive genetic random regression coefficients matrix $\left(\mathbf{K}_{a}\right)$ of second-order Legendre polynomials

\begin{tabular}{lccc}
\hline $\begin{array}{l}\text { Term of Legendre } \\
\text { polynomial }\end{array}$ & Eigenvector 1 & Eigenvector 2 & Eigenvector 3 \\
\hline Constant & 0.9692 & -0.0222 & 0.2452 \\
Linear & 0.2110 & 0.5877 & -0.7811 \\
Quadratic & -0.1267 & 0.8088 & 0.5743 \\
\hline
\end{tabular}

second and third eigenvector indices were added to the first ( $\mathrm{IS}_{2}$ and $\mathrm{IS}_{3}$, respectively), we observed a tendency for the genetic gains for persistency to increase and a tendency for genetic gains for milk yield to decrease when the relative economic weights ranged from $q_{1}: q_{2}$ $=1: 1$ to $q_{1}: q_{2}=1: 100$. These tendencies were explained by the changes of the estimates of the coefficients of the indices when the relative economic weights of milk yield and persistency were changed. These results indicate that if the breeding goal is to improve milk yield and persistency, additional genetic gains in persistency and high genetic gain for milk yield could be obtained using the complete sequential eigenvector indices with relative weights above $q_{1}: q_{2}=1: 75$. However, more studies about economic weights for persistency are necessary to verify if these relative weights are economically viable. If the breeding goal is to improve only milk yield, the traditional selection index could be used because it is simple to calculate. When persistency is defined as in this study (EBV at 280 DIM - EBV at 60 DIM), it will also present a certain genetic gain even if the breeding goal is milk production alone $\left(\mathrm{I}_{M Y 305}\right.$ in Table 7$)$.

\section{CONCLUSIONS}

The coefficients of the selection indices based on eigenvectors of $\mathbf{K}_{a}$ were obtained according to the importance of the eigenvalues of this matrix, not empirically,

Table 7. Genetic gain $(\mathrm{kg})$ using individual and sequential eigenvector indices and the traditional selection index for milk production

\begin{tabular}{|c|c|c|c|c|}
\hline \multirow[b]{2}{*}{ Criterion $^{1}$} & \multicolumn{4}{|c|}{ Genetic gain ${ }^{2}$} \\
\hline & $\Delta G_{L}$ & $\Delta G_{P}$ & $\Delta G_{60}$ & $\Delta G_{280}$ \\
\hline \multicolumn{5}{|l|}{ Individual eigenvector indices } \\
\hline $\mathrm{I}_{1}=\mathrm{x} 1$ & 670.99 & 0.95 & 1.63 & 2.58 \\
\hline $\mathrm{I}_{2}=\mathrm{x} 2$ & -3.9 & 1.81 & -0.38 & 1.43 \\
\hline $\mathrm{I}_{3}=\mathrm{x} 3$ & 43.78 & -0.83 & 0.72 & -0.11 \\
\hline \multicolumn{5}{|l|}{ Sequential eigenvector indices with $q_{1}: q_{2}=1: 1$} \\
\hline $\mathrm{IS}_{1}=205.09 \times 1$ & 670.99 & 0.95 & 1.63 & 2.58 \\
\hline $\mathrm{IS}_{2}=205.09 \times 1-2.76 \times 2$ & 671 & 0.94 & 1.63 & 2.57 \\
\hline $\mathrm{IS}_{3}=205.09 \times 1-2.76 \times 2+51.35 \times 3$ & 672.43 & 0.88 & 1.68 & 2.56 \\
\hline \multicolumn{5}{|c|}{ Sequential eigenvector indices with $q_{1}: q_{2}=1: 25$} \\
\hline $\mathrm{IS}_{1}=212.07 \mathrm{x} 1$ & 670.99 & 0.95 & 1.63 & 2.58 \\
\hline $\mathrm{IS}_{2}=212.07 \times 1+36.08 \times 2$ & 669.6 & 1.05 & 1.61 & 2.66 \\
\hline $\mathrm{IS}_{3}=212.07 \times 1+36.08 \times 2+27.27 \times 3$ & 670.71 & 1.02 & 1.63 & 2.65 \\
\hline \multicolumn{5}{|l|}{ Sequential eigenvector indices with $q_{1}: q_{2}=1: 50$} \\
\hline $\mathrm{IS}_{1}=219.34 \times 1$ & 670.99 & 0.95 & 1.63 & 2.58 \\
\hline $\mathrm{IS}_{2}=219.34 \times 1+76.54 \times 2$ & 665.64 & 1.15 & 1.58 & 2.73 \\
\hline $\mathrm{IS}_{3}=219.34 \times 1+76.54 \times 2+2.18 \times 3$ & 665.84 & 1.15 & 1.58 & 2.73 \\
\hline \multicolumn{5}{|c|}{ Sequential eigenvector indices with $q_{1}: q_{2}=1: 75$} \\
\hline $\mathrm{IS}_{1}=226.61 \mathrm{x} 1$ & 670.99 & 0.95 & 1.63 & 2.58 \\
\hline $\mathrm{IS}_{2}=226.61 \times 1+117.00 \times 2$ & 660.06 & 1.25 & 1.54 & 2.79 \\
\hline $\mathrm{IS}_{3}=226.61 \times 1+117.00 \times 2-22.91 \times 3$ & 658.72 & 1.27 & 1.52 & 2.79 \\
\hline \multicolumn{5}{|c|}{ Sequential eigenvector indices with $q_{1}: q_{2}=1: 100$} \\
\hline $\mathrm{IS}_{1}=233.87 \times 1$ & 670.99 & 0.95 & 1.63 & 2.58 \\
\hline $\mathrm{IS}_{2}=233.87 \times 1+157.46 \times 2$ & 652.93 & 1.33 & 1.5 & 2.83 \\
\hline $\mathrm{IS}_{3}=233.87 \times 1+157.46 \times 2-48.00 \times 3$ & 649.92 & 1.37 & 1.47 & 2.84 \\
\hline \multicolumn{5}{|l|}{ Traditional selection index } \\
\hline $\mathrm{I}_{M Y 305}$ & 672.40 & 1.13 & 1.82 & 2.95 \\
\hline
\end{tabular}

${ }^{1} \mathrm{I}_{j}=$ selection index based on the $j$ th individual eigenvector; $\mathrm{IS}_{n}=$ selection index for $n$ sequential eigenvectors; $q_{1}$ and $q_{2}=$ economic weights for milk yield and persistency, respectively; $\mathrm{I}_{M Y 305}=$ traditional selection index. ${ }^{2} \Delta G_{L}=$ genetic gain for milk production from 5 to 305 DIM; $\Delta G_{P}=\Delta G_{60}-\Delta G_{280}=$ genetic gain for persistency of milk production; $\Delta G_{60}=$ genetic gain for milk production at $60 \mathrm{DIM} ; \Delta G_{280}=$ genetic gain for milk production at 280 DIM. 
taking into account the genetic covariance between the additive coefficients of the RR model in the calculation of the weights. The first individual eigenvector index improved mainly milk yield, because the higher coefficient of this eigenvector is associated with the constant term of Legendre polynomials. The second individual eigenvector index was more related to genetic gains for persistency, but it would result in negative genetic gains for total milk yield. Therefore, in general, using this eigenvector to improve persistency will not contribute to change the shape of genetic curve pattern. If the breeding goal is to improve milk production and persistency, complete sequential eigenvector indices $\left(\mathrm{IS}_{3}\right)$ should be used with relative economic weights above $\mathrm{q}_{1}: \mathrm{q}_{2}=1: 75$, because this model resulted in higher genetic gains for persistency compared with the traditional selection index. If the breeding goal is to improve only milk yield, the traditional selection index is indicated.

\section{ACKNOWLEDGMENTS}

We thank CRV Lagoa (Sertãozinho, São Paulo, Brazil) for providing the data used in this study. $\mathrm{R}$. P. Savegnago was granted scholarships by the São Paulo Research Foundation (FAPESP; Fundação de Amparo à Pesquisa do Estado de São Paulo - Scholarship 2010/05148-8 and 2012/16087-5). L. G. G. Herrera received scholarships from the Coordination Office for Advancement of University-Level Personnel (CAPES; Coordenação de Aperfeiçoamento de Pessoal de Nível Superior) in conjunction with the Postgraduate Program on Genetics and Animal Breeding, Faculdade de Ciências Agrárias e Veterinárias, Universidade Estadual Paulista (FCAV-UNESP). L. El Faro and D. P. Munari held productivity research fellowships from the National Council for Scientific and Technological Development (CNPq; Conselho Nacional de Desenvolvimento Científico e Tecnológico).

\section{REFERENCES}

Araújo, C. V., R. A. Torres, C. N. Costa, R. A. Torres-Filho, S. I. Araújo, P. S. Lopes, A. J. Regazzi, C. S. Pereira, and J. L. R. Sarmento. 2006. Random regressions models to describe the genetic variation of milk yield in Holstein breed. R. Bras. Zootec. 35:967-974.

Bignardi, A. B., L. El Faro, V. L. Cardoso, P. F. Machado, and L. G. Albuquerque. 2009. Random regression models to estimate testday milk yield genetic parameters Holstein cows in Southeastern Brazil. Livest. Sci. 123:1-7.

Bignardi, A. B., L. El Faro, G. J. M. Rosa, V. L. Cardoso, P. F. Machado, and L. G. Albuquerque. 2012. Principal components and factor analytic models for test-day milk yield in Brazilian Holstein cattle. J. Dairy Sci. 95:2157-2164.

Bignardi, A. B., L. El Faro, R. A. A. Torres Júnior, V. L. Cardoso, P. F. Machado, and L. G. Albuquerque. 2011. Random regression models using different functions to model test-day milk yield of Brazilian Holstein cows. Genet. Mol. Res. 10:3565-3575.
Brotherstone, S., I. M. S. White, and K. Meyer. 2000. Genetic modeling of daily milk yields using orthogonal polynomials and parametric curves. J. Anim. Sci. 70:407-415.

Cobuci, J. A., R. F. Euclydes, P. S. Lopes, C. N. Costa, R. A. Torres, and C. S. Pereira. 2005. Estimation of genetic parameters for testday milk yield in Holstein cows using a random regression models. Genet. Mol. Biol. 28:75-83.

Cole, J. B., and D. J. Null. 2009. Genetic evaluation of lactation persistency for five breeds of dairy cattle. J. Dairy Sci. 92:2248-2258.

Cole, J. B., and P. M. VanRaden. 2006. Genetic evaluation and best prediction of lactation persistency. J. Dairy Sci. 89:2722-2728.

Dekkers, J. C. M., J. H. Ten Haag, and A. Weersink. 1997. Economic aspects of persistency in dairy cattle. Livest. Prod. Sci. 53:237252.

Druet, T., F. Jaffreézic, and V. Ducrocq. 2005. Estimation of genetic parameters for test day records of dairy traits for the first three lactations. Genet. Sel. Evol. 37:257-271.

Druet, T., F. Jaffrézic, D. Boichard, and V. Ducrocq. 2003. Modeling lactation curves and estimation of genetic parameters for first lactation test-day records of French Holstein cows. J. Dairy Sci. $86: 2480-2490$

Dzomba, E. F., K. A. Nephawe, A. N. Maiwashe, S. W. P. Cloete, M Chimonyo, C. B. Banga, C. J. C. Muller, and K. Dzama. 2010. Random regression test-day model for the analysis of dairy cattle production data in South Africa: Creating the framework. S. Afr. J. Anim. Sci. 40:273-284.

El Faro, L., and L. G. Albuquerque. 2003. Random regression test-day models for milk yield records, with different structure of residual variances. R. Bras. Zootec. 32:1104-1113.

Fischer, T. M., A. R. Gilmour, and J. H. J. Van der Werf. 2004. Computing approximate standard errors for genetic parameters derived from random regression models fitted by average information REML. Genet. Sel. Evol. 36:363-369.

Gengler, N. 1995. Use of mixed models to appreciate the persistency of yields during the lactation of milk cows. PhD Thesis. Faculté Universitaire des Sciences Agronomiques de Gembloux, Gembloux, Belgium.

Gengler, N. 1996. Persistency of lactation: A review. Interbull Bull. 12:87-96.

Grossman, M., S. M. Hartz, and W. J. Koops. 1999. Persistency of lactation yield: A novel approach. J. Dairy Sci. 82:2192-2197.

Henderson, C. R., Jr. 1982. Analysis of covariance in the mixed model: Higher-level, nonhomogeneous and random regressions. Biometrics 38:623-640.

Jamrozik, J., G. J. Kistemaker, J. C. M. Dekkers, and L. R. Schaeffer. 1997. Comparison of possible covariates for use in a random regression model for analyses of test day yields. J. Dairy Sci. 80:2550-2556

Jamrozik, J., and L. R. Schaeffer. 1997. Estimates of genetic parameters for a test day model with random regressions for yield traits of first lactation Holsteins. J. Dairy Sci. 80:762-770.

Jensen, J. 2001. Genetic evaluation of dairy cattle using test-day models. 2001. J. Dairy Sci. 84:2803-2812.

Kettunen, A., E. A. Mäntysaari, and J. Pösö. 2000. Estimation of genetic parameters for daily milk yield of primiparous Ayrshire cows by random regression test-day models. Livest. Prod. Sci. $66: 251-261$.

Kirkpatrick, M., W. G. Hill, and R. Thompson. 1994. Estimating the covariance structure of traits during growth and aging, illustrated with lactations in dairy cattle. Genet. Res. 64:57-69.

Kirkpatrick, M., and D. Lofsvold. 1992. Measuring selection and constraint in the evolution of growth. Evolution 46:954-971.

Kirkpatrick, M., D. Lofsvold, and M. Bulmer. 1990. Analysis of the inheritance, selection and evolution of growth trajectories. Genetics 124:979-993.

Lin, C. Y., and K. Togashi. 2005. Maximization of lactation milk production without decreasing persistency. J. Dairy Sci. 88:29752980.

Meyer, K. 2007. WOMBAT - A tool for mixed model analyses in quantitative genetics by restricted maximum likelihood (REML). J. Zhejiang Univ. Sci. B 8:815-821. 
Mrode, M. A. 2005. Linear Models for the Prediction of Animal Breeding Values. 2nd ed. CABI Publishing, Wallingford, UK.

Olori, V. E., W. G. Hill, B. J. McGuirk, and S. Brotherstone. 1999. Estimating variance components for test day milk records by restricted maximum likelihood with a random regression animal model. Livest. Prod. Sci. 61:53-63.

Pool, M. H., L. L. G. Janss, and T. H. E. Meuwissen. 2000. Genetic parameters of Legendre polynomials for first parity lactation curves. J. Dairy Sci. 83:2640-2649.

Ptak, E., and L. R. Schaeffer. 1993. Use of test day yields for genetic evaluation of dairy sires and cows. Livest. Prod. Sci. 34:23-34.

Reeve, E. C. R. 1955. The variance of the genetic correlation coefficient. Biometrics 11:357-374.

Rekaya, R., M. J. Carabaño, and M. A. Toro. 1999. Use of test day yields for the genetic evaluation of production traits in HolsteinFriesian cattle. Livest. Prod. Sci. 57:203-217.

Robertson, A. 1959. The sampling variance of the genetic correlation coefficient. Biometrics 15:469-485.

SAS Institute. 2008. SAS/STAT 9.2 User's Guide. SAS Institute Inc., Cary, NC.

Schaeffer, L. R. 2004. Application of random regression models in animal breeding. Livest. Prod. Sci. 86:35-45.

Schwarz, G. 1978. Estimating the dimension of a model. Ann. Stat. 6:461-464.

Strabel, T., and I. Misztal. 1999. Genetic parameters for first and second lactation milk yields of Polish black and white cattle with random regression test-day models. J. Dairy Sci. 82:2805-2810.
Swalve, H. H. 2000. Theoretical basis and computational methods for different test-day genetic evaluation models. J. Dairy Sci. 83:1115-1124.

Swalve, H. H., and N. Gengler. 1999. Genetics of lactation persistency. Pages $75-82$ in Metabolic Stress in Dairy Cows. J. D. Oldham, G. Simm, A. F. Groen, B. L. Nielsen, J. E. Pryce, and T. L. J. Lawrence, ed. BSAS Occasional Publication 24. Br. Soc. Anim. Sci., Penicuik, UK.

Togashi, K., and C. Y. Lin. 2004. Efficiency of different selection criteria for persistency and lactation milk yield. J. Dairy Sci. $87: 1528-1535$

Togashi, K., and C. Y. Lin. 2006. Selection for milk production and persistency using eigenvectors of the random regression coefficient matrix. J. Dairy Sci. 89:4866-4873.

van der Werf, J. H. J., M. E. Goddard, and K. Meyer. 1998. The use of covariance functions and random regressions for genetic evaluation of milk production based on test day records. J. Dairy Sci. 81:3300-3308.

VanRaden, P. M. 1998. Best prediction of lactation yield and persistency. Pages 347-350 in Proc. 6th World Congr. Genet. Appl. Livest. Prod., Armidale, Australia. University of New England, Armidale, Australia. 